\title{
El impacto de la actividad de consultoría sobre la capacidad institucional de las Administraciones públicas de los países de América Latina*
}

\section{Carles Ramió Matas**}

\section{Introducción}

La existencia y el buen funcionamiento de un Estado moderno es un elemento clave para garantizar la sostenibilidad de cualquier proceso de desarrollo. El denominado desarrollo institucional pretende contribuir a reforzar las instituciones públicas y sus relaciones con el entorno político y social para mejorar los resultados de la acción pública y asegurar la gobernabilidad. Los proyectos de desarrollo o refuerzo institucional pueden contribuir al éxito de los procesos de transición democrática, de reforma del Estado o de construcción de una fiable economía de mercado en los países de América Latina. Estas actividades suelen estar protagonizadas por consultores que dan apoyo a procesos de construcción de sistemas de servicio civil, de reforma institucional, de modernización administrativa, de reforma educativa, sanitaria, policial, judicial, fiscal y, en general, de diseño o rediseño de políticas públicas. Este apoyo suele tomar cuerpo en tareas de asesoramiento a autoridades públicas, elaboración de informes y diagnósticos e impartición de acciones públicas, teniendo como beneficiarios directos a gobiernos e instituciones públicas o parapúblicas de los países en transición o desarrollo como es el caso de los Estados de América Latina.

Es evidente que España ha experimentado durante las últimas décadas unos cambios extraordinarios a nivel político y administrativo. En el contexto internacional nuestra transición política, nuestro original proceso de descentralización, y diversas y significativas prácticas de innovación de nuestras administraciones públicas se han convertido en modelos de referencia. En este sentido, España ha pasado de la autarquía a nivel político y administrativo a participar y contribuir en el debate globalizado de la mejora de la democracia y de las instituciones administrativas. Y no sólo nos hemos limitado a participar en estos debates mundiales de forma más o menos pasiva, sino que hemos logrado ser un país con capacidad para exportar algunas de nuestras experiencias políticas y de gestión pública a otros países. Nuestro principal mercado de influencia es lógicamente América Latina. Los países de esta región y las organizaciones internacionales que colaboran en su desarrollo observan con interés nuestros avances en gestión pública, ya que muchos de ellos pueden aplicarse por su proximidad en el modelo de administración y en la cultura social y administrativa de estos países.

En las últimas décadas la actividad de consultoría institucional de los países desarrollados hacia los países en vías de desarrollo, como los de la región de América Latina, se ha visto multiplicada de forma extraordinaria. Esta actividad está auspiciada y financiada por los propios países de la región, por los países desarrollados en el marco de sus actividades de cooperación al desarrollo y por organismos supranacionales (programas MEDA, ALA, PHARE, TACIS y ACP de la Unión Europea) y por organismos internacionales (Banco Mundial, Bancos Regionales de Desarrollo entre los que destaca el BID, PNUD de Naciones Unidas, etc.). A España le está resultando muy difícil entrar en este mercado de consultoría internacional fundamentalmente por la falta de tradición y experiencia de nuestras consultoras pri- 
vadas, de nuestras administraciones públicas y de nuestras universidades en desarrollar programas de consultoría internacional. Por ejemplo, España está muy lejos en esta materia en comparación con países de referencia como Francia, Alemania, Gran Bretaña, etc. España contribuye económicamente de forma muy importante en los diversos organismos internaciones que impulsan programas para el desarrollo pero no logra el mismo protagonismo en el diseño e implementación técnica de estos programas (los especialistas denominan esta situación como tasa de retorno muy baja). La ejecución técnica de los programas públicos de desarrollo en los países en transición es una actividad muy estratégica para cualquier país desarrollado. En este sentido, a nadie se le escapa que diseñar un modelo determinado de Administración, una determinada política de regulación, un sistema concreto de prestación de bienes públicos, etc., genera una ventaja competitiva a nivel económico (para sus empresas multinacionales) y político para el país desarrollado que ha sido el modelo de referencia. No deja de sorprender este déficit de la presencia española en consultoría institucional en América Latina cuando una parte significativa de sus más potentes entidades financieras e industriales llevan más de una década con una presencia muy significativa en esta región.

De todos modos, este déficit evidente de nuestra presencia en el mercado latinoamericano de consultoría internacional en el ámbito público está siendo superado, durante los últimos años, y cada vez es más numerosa la presencia de consultores españoles en América Latina, sin dejar de lado su participación en proyectos en los países de Este de Europa y en algunos países africanos que es mucho menor pero significativa. Cada vez hay más consultoras privadas de capital español que se mueven con fluidez por los laberintos de Bruselas y Washington y no es nada extraño que algunas de nuestras administraciones hagan actividades de consultoría internacional (destacan la Administración General del Estado con el FIIAP y algunas corporaciones locales de referencia), así como algunas universidades públicas y privadas. Incluso hay un postgrado universitario en la Universidad Pompeu Fabra, Diploma de Postgrado en Consultoría Internacional para el Desarrollo Institucional, que tiene como objetivo formar a futuros consultores y gestores de proyectos de asistencia técnica internacional al sector público en los países en desarrollo y en transición.

Dentro de este emergente contexto el objetivo de este artículo es presentar un conjunto de reflexiones críticas de carácter conceptual y práctico sobre el papel y el desarrollo profesional de la consultoría internacional especializada en el ámbito público. La arquitectura del artículo agrupa cuatro apartados. El primer apartado hace una reflexión general sobre la consultoría española en los países de América Latina (Vender España en América Latina) en la que se presentan los valores que guiarán el resto del artículo. El segundo apartado hace referencia a las coincidencias y a las diferencias entre la consultoría donde consultores y instituciones receptoras de esta actividad pertenecen a un mismo país (consultoría intra-nacional) y la consultoría internacional en la que usualmente los consultores pertenecen a un país (mayoritariamente un país desarrollado) y las instituciones públicas receptoras a un país diferente (mayoritariamente un país en transición o desarrollo). El tercer apartado conceptualiza, utilizando parcialmente la corriente académica del neoinstitucionalismo, los problemas de la consultoría internacional que origina que una parte importante de esta actividad no sea útil y, por tanto, no aporte valor añadido a las organizaciones públicas de los países en desarrollo. Finalmente, el cuarto apartado se mueve en un plano normativo y presenta un conjunto de propuestas tentativas para conseguir que la actividad de consultoría internacional del ámbito público pueda se útil para los países de América Latina.

\section{Crítica general a la actividad de consultoría institucional española para los países de América Latina: "Vender España en América Latina"}

Desde Europa sorprenden las periódicas crisis que acontecen en los Estados de América Latina. Cuando un país parece que ha encontrado la senda correcta orientada a superar los problemas económicos y de gobernabilidad (por ejemplo, Argentina, Brasil, Perú o Ecuador) no tarda mucho tiempo en sufrir una inesperada y espectacular recaída. Los economistas nos pueden hablar de ciclos económicos pero lo que sucede en esta región del mundo nada tiene que ver con los ciclos que estamos acostumbrados a vivir en los países más avanzados. Pueden complementar el diagnóstico introduciendo el concepto de debilidad económica e institucional pero ésta es sólo un síntoma y no la enfermedad. Es bastante común confundir simples síntomas con enfermedades. La pregunta que debemos formularnos es: ¿cuál es la enfermedad crónica de los países de América Latina?

Uno de los problemas fundamentales de los países de América Latina es que desde sus procesos de independencia se han inspirado en su vecino del norte, los Estados Unidos. Por ejemplo, optaron por modelos políticos de carácter presidencial, con modelos de Estado federales, etc. Todo a imagen y semejanza de la entonces emergente potencia mundial. Pero los modelos políticos e institucionales de estos países de América Latina 
nunca funcionaron realmente como el de Estados Unidos. Los presidencialismos eran dictaduras encubiertas, los modelos federales operaban de una forma totalmente centralista. Las instituciones formales políticas y administrativas estaban sólo en la Constitución y la realidad funcionan con base a los parámetros de cultura política y social asociada a una estructura de elites que nada tenía que ver con la de los Estados Unidos. Esta tradición histórica de copiar a los Estados Unidos se ha mantenido hasta nuestros días. Se imitan no sólo las instituciones políticas y administrativas sino también las instituciones económicas y sociales. Pero, dejando de lado las dificultades específicas de implantar el modelo norteamericano, el problema fundamental reside en la tendencia de los países latinoamericanos a copiar, a buscar fuera la solución a sus problemas y a no edificar desde sus realidades modelos de reforma y modernización.

En los últimos años se percibe que en los países de esta enorme región mundial hay un cansancio en mirarse al espejo de los Estados Unidos y se empieza a mirar a Europa y, más en concreto, a España. Este país se está configurando como una referencia alternativa a los Estados Unidos. El éxito democrático, económico, social y de descentralización de España no ha pasado inadvertido. También influye la espectacular presencia de empresas hispanas en los países latinoamericanos. Las ventajas de adoptar a España como modelo son muy amplias: vínculos históricos y culturales, idioma, etc. Para los españoles es una gran oportunidad no para practicar un renovado colonialismo sino para colaborar y contribuir en el desarrollo de estos países culturalmente próximos sin negar que ello pueda estar vinculado a reforzar nuestra presencia política y económica en esta región en expansión.

Pero todo parece indicar que españoles y latinoamericanos estamos cayendo en el mismo error de antes ya que no se trata de cambiar el espejo de los Estados Unidos por el de España sino que la transformación debe ser más intensa. No se trata, como se ha intentado, de ofrecer y vender el proceso español de transición hacia la democracia o su proceso de descentralización. Estos procesos son totalmente autóctonos y no tienen ningún tipo de utilidad, salvo el estrictamente intelectual, en los países de América Latina. Estas diferencias ya se han demostrado pero, en cambio, se sigue con la obsesión en ofrecer estos supuestos éxitos hispanos para que sean copiados sin matices ni esfuerzos de contextualización. Los consultores, los académicos y las instituciones públicas españolas han pasado de vender transiciones y descentralizaciones a vender modelos sanitarios, sistemas de servicios sociales, modelos de ciudad, etc. Pero, por ejemplo, ¿qué tiene que ver Barcelona como modelo de ciudad con Bogotá, Sao Paulo o Managua? ¿Qué posibilidades tiene en América Latina el modelo sanitario catalán basado en un maduro sector privado? Seguimos con el juego del espejo que de nada puede servir a los países de América Latina.

Lo que se debería hacer, aprovechando nuestros puntos de contacto culturales y de idioma, es ofrecer nuestros conocimientos profesionales para contribuir al desarrollo político, económi- co e institucional de los países de América Latina. Pero antes debe comprenderse su historia, su compleja organización política y social y adaptar nuestros conocimientos y modelo de desarrollo a sus problemas y contextos concretos. Debemos de bajar del estrado desde donde imponemos nuestros modelos y contribuir con los expertos de estos países a edificar sus propios modelos de sanidad, de protección social, de ciudad, etc. Esta orientación no colonialista de la cooperación ya la han adoptado algunas instituciones públicas y organizaciones no gubernamentales pero debe intensificarse y, especialmente, debe profesionalizarse. En definitiva, no sólo se trata de vender menos y colaborar más sino también de hacer menos turismo cultural y de trabajar con más sentido de la profesionalidad.

\section{Los problemas específicos de la consultoría intra-nacional en relación con la consultoría internacional}

Antes de entrar en el apartado nuclear del artículo, que tiene por objeto analizar la situación y la problemática de la consultoría internacional para las instituciones públicas de los países de América Latina, se van a presentar sintéticamente los problemas vinculados a la actividad de consultoría intra-nacional (en la que el consultor y la institución pública objeto de estudio pertenecen al mismo contexto nacional). El objetivo es demostrar que los problemas de la consultoría institucional no se producen sólo cuando ésta adquiere una dimensión internacional sino que también existen a nivel nacional. La mayoría de estos problemas vinculados a la consultoría intra-nacional también se producen en la consultoría internacional pero ésta tiene unas especificidades que posibilita que algunos de estos problemas, detectados a nivel nacional, se transformen en oportunidades a nivel internacional y, más en concreto, en el contexto de los países de América Latina.

\subsection{Los problemas vinculados a la actividad de consultoría en el sector público en el ámbito intra-nacional}

La participación de las consultoras privadas en los procesos de cambio institucional de las organizaciones públicas presenta, en determinadas situaciones, varios problemas que son difíciles de superar (RAMIÓ, 2002): 
1) Las especificidades propias de las organizaciones públicas suelen ser mal comprendidas por las consultoras externas

La mayoría de las consultoras que trabajan para el sector público suelen emplear un bagaje conceptual y un instrumental metodológico basado en los problemas y las transiciones de mejora de organizaciones privadas sin tener en cuenta las evidentes especificidades de las administraciones públicas como organizaciones (recordemos la frase de ALISON: la gestión pública y la gestión privada se parecen mucho en los aspectos poco relevantes). Con el tiempo las consultoras que trabajan en el sector público han ido comprendiendo las especificidades de la gestión pública e incrementalmente han ido armando unos conceptos e instrumentos específicos orientados a analizar y mejorar las organizaciones públicas. Este positivo cambio de concepción se ha visto truncado por el influjo negativo en los años noventa de la Nueva Gestión Pública ya que esta corriente propone el acercamiento de la gestión pública a la gestión privada (RAMió, 2001). Es decir, actualmente las consultoras han regresado a sus conceptos e instrumental orientado a organizaciones privadas pero con la legitimidad de las modernas concepciones de la gestión pública. El hipotético progreso de la Nueva Gestión Pública ha generado un escenario de regresión conceptual y metodológica en el ámbito de la consultoría de instituciones públicas, ya que se ha vuelto a actitudes, conceptos e instrumentos del pasado que había costado mucho tiempo y esfuerzo superar.

\section{2) Los agentes externos pueden generar una mayor resistencia en} los empleados públicos a ser investigados y a modificar sus pautas de trabajo

Las consultoras llevan muchos años prestando sus servicios a las administraciones públicas. Una colaboración que al principio era percibida por los funcionarios públicos con interés por su novedad ha ido degenerando en situaciones muy negativas. Actualmente los funcionarios públicos ven con mucho recelo la figura de los consultores y sus aportaciones ya que:

- Consideran que buena parte de los productos generados por las consultoras carecen de calidad suficiente 0 que, en todo caso, ellos (los funcionarios) lo habrian hecho mejor.

- Se considera que es injusto que se vaya a buscar experiencia fuera cuando existe suficiente capacidad en el interior de las instituciones públicas objeto de reforma.

- Los funcionarios se sienten menospreciados por los directivos políticos que atienden más los consejos de los agentes externos que las consideraciones de los agentes internos.
Hay muchos más elementos en juego que conducen al resultado común que los consultores incentivan recelos y sus propuestas generan resistencias no tanto vinculadas a los contenidos sino, más bien, ligadas a problemas de legitimidad, de distribución de papeles entre los agentes internos y los externos, entre la dimensión política y la profesional, etc.

3) Existe una mayor dificultad técnica para que las consultoras externas puedan abarcar el circuito de cambio completo (especialmente para participar en el proceso de implementación del nuevo modelo organizativo propuesto)

La actividad de consultoría suele circunscribirse en la dicotomía diagnóstico - propuesta. Los consultores elaboran un diagnóstico en el que destacan los puntos débiles o disfunciones detectadas y, posteriormente, diseñan un modelo de gestión alternativo orientado a superar las disfunciones detectadas y maximizar las fortalezas. Casi nunca los consultores se encargan de pilotar el proceso de implementación de las propuestas que elaboran (monitorización del cambio), esta puesta en práctica es una función reservada a los miembros (empleados públicos) de la organización pública objeto de consultoría. El problema que se deriva en que los consultores finalicen sus actividades con las propuestas de mejora organizativa es que tienden a ser idealistas o maximalistas en el contenido de sus propuestas. Éste es un problema inevitable ya que los consultores generan un producto final (propuesta de modelo de gestión alternativo) que representa la aportación por la que son evaluados por sus clientes. Cuanto más innovadora es la propuesta mejor se valora la actividad de la consultora. Pero elaborar propuestas maximalistas para las organizaciones públicas es un grave error ya que tienen muchas dificultades para ser implementadas debido a problemas relacionados con el contexto de la organización y, también, con sus capacidades internas. Es mayoritario el escenario en que una consultora presenta una propuesta organizativa muy bien planteada a nivel teórico que implica unas grandes mejoras mediante un modelo alternativo de gestión muy innovador, en la que la organización receptora del informe está encantada con el mismo pero que ésta, después de la intervención de la consultora, es incapaz de implementar el modelo propuesto. Plantear cambios maximalistas en el sector público siempre choca con problemas legales, políticos, de resistencias corporativas, etc., que suelen bloquear sin matices los procesos de transformación.

\section{4) Los servicios de las consultoras externas suelen ser muy costo- sos en recursos económicos y en tiempo}

La actividad de consultoría supone una fuerte inversión de tiempo para conseguir que los consultores puedan comprender las especificidades organizativas y de contexto de 
la organización objeto de estudio. El tiempo dedicado por estos profesionales de alto nivel genera unos costes económicos muy importantes que debe afrontar la organización pública objeto de estudio. Atendiendo a todos estos costes las solicitudes de actividades de consultoría deberían siempre estar bien fundamentadas por la magnitud y complejidad de los problemas que sufre la organización y por la incapacidad de solucionar estos problemas desde dentro por déficits profesionales o bien por prejuicios, subjetividades y conflictos internos de intereses. Además, sólo se debería recurrir a una consultoría institucional cuando la organización objeto de análisis estuviera madura y preparada (a nivel político, profesional y de entorno) para absorber una estrategia de cambio organizativo.

5) El principal problema que se percibe sobre la intervención de las consultoras privadas en este proceso es la discutible objetividad de sus análisis y conclusiones

La tendencia general es que los diagnósticos y las propuestas presentadas por las consultoras sean elaborados a la medida del cliente, entendiendo cliente no a la Administración pública a la que prestan sus servicios sino al órgano o persona que ha contratado directamente a la consultora. Este órgano o persona tiene unos intereses propios y específicos que no coinciden necesariamente con los objetivos generales de la organización pública objeto de estudio. Las consultoras, como empresas privadas que son, buscan la satisfacción de su cliente (que siempre es en la práctica una/s persona/s) para que éste les encargue nuevos estudios o al menos muestre su satisfacción con los resultados obtenidos al resto de actores administrativos los cuales son potenciales clientes. En este sentido, la participación de una consultora en un proceso de cambio organizativo origina que la persona o instancia administrativa que posea un análisis organizativo elaborado por una consultora (y más si ésta posee renombre y prestigio) esté en mejor situación para negociar o imponer sus criterios organizativos, sin que esta circunstancia vaya unida necesariamente a unas mejores garantías técnicas.

\section{6) Se imprime excesiva importancia y valor al management público}

Se da una excesiva importancia al managament, a planteamientos estrictamente tecnocráticos, sin tener en cuenta que son sólo instrumentos que sirven para determinados ámbitos (hay que resaltar que no todos) pero que no son capaces de solucionar los grandes problemas que deben afrontar las instituciones públicas. Además el management público (y mucho más el management privado) tiene una dimensión oscura que origina que una parte de sus planteamientos responden más a modas, a marketing y a intereses económicos que a planteamientos académicos que aseguren un avance en el rendimiento institucional de las Administraciones públicas (HooD, 1998; MickletheWAIT, WoOLDRIEGE, 1998). En todo caso es evidente que el management público puede procurar eficacia y eficiencia en la provisión de bienes públicos divisibles a "clientes" individualizados. Esto es importante pero el management público por sí mismo no genera un sistema de seguridad jurídica y de confianza y con ello proveer la eficiencia general del mercado público y contribuir a generar eficiencia al mercado privado de un determinado entorno nacional. En síntesis, el management público no tiene capacidad para generar por sí mismo suficiente valor añadido para diseñar o rediseñar instituciones públicas que se adapten a los problemas más importantes de su entorno.

\subsection{Las oportunidades de la consultoría internacional}

En un principio, y en un plano conceptual, las especificidades de la consultoría internacional no implican de forma automática más problemas y dificultades que la consultoría de carácter nacional. Más bien al contrario, la consultoría internacional presenta dos grandes ventajas con relación a la consultoría intra-nacional:

\section{1) La distancia entre consultor y objeto de estudio}

En la consultoría internacional existe la ventaja que la distancia física y de contexto corporativo y social entre el consultor y la institución pública objeto de estudio facilitan al máximo una relación de carácter profesional donde, en teoría, no prevalecen los prejuicios, ni el subjetivismo ni las interferencias de intereses inherentes en buena parte de las actividades de consultorías de carácter nacional. Se puede argumentar que la distancia entre el sujeto activo (consultor) y el objeto (administración pública) facilita una actividad más neutral y científica. De todos modos, en la práctica la consultoría institucional internacional agrupa un complejo espectro de variables que potencialmente pueden interferir muy negativamente en la calidad de esta actividad.

\section{2) Las posibilidades reales de mejorar e innovar la gestión de las organizaciones públicas objeto de estudio}

En los países más desarrollados los sistemas administrativos poseen unas rigideces derivadas de una combinación entre modelos de Estado (MARCH, OLSEN, 1997) institucionales (existen unos valores y unas creencias compartidas que dificultan los cambios y las innovaciones) y de Estado corporativo (los fundamentos son la negociación y el compromiso entre distintos grupos internos y externos a la administración pública situación que no favorece los cambios y la innovación). Es decir, las administraciones públicas de los países desarrollados, básicamente los europeos, representan sistemas tan maduros y consolida- 
dos que es muy difícil introducir cambios e innovaciones significativas. En este contexto la actividad de las consultoras de carácter institucional sólo puede aspirar a cambios e innovaciones incrementalistas o marginales. Un ejemplo de esta situación serían los rígidos sistemas de servicio civil que suponen una barrera muy difícil de superar para los cambios e innovaciones administrativas.

En cambio, la situación de los sistemas administrativos de la mayoría de los países de América Latina es totalmente distinta. Aparentemente estamos ante Estados corporativos bastante inamovibles pero que al asentarse sobre unas bases muy informales son en realidad muy flexibles. Además, son Estados escasamente institucionalizados ya que no existen ni valores ni creencias compartidas y carecen de modelos efectivos de servicio civil de carrera. Finalmente, el contacto con la Nueva Gestión Pública, que defiende una desinstitucionalización orientada a la consecución de una flexibilidad vinculada a un modelo postburocrático, ha contribuido a configurar organizaciones públicas escasamente institucionalizadas.

Estas características de los sistemas administrativos de los países de América Latina son muy negativas y configuran un cuello de botella institucional que frena el desarrollo económico y social en la región. Pero este problema, en el contexto de la consultoría internacional, implica una enorme oportunidad ya que es posible implementar los cambios y las innovaciones radicales que puedan proponer los consultores. Una vez las elites políticas y administrativas están convencidas de las bondades del modelo de gestión propuesto por los consultores su implementación es mucho más sencilla que en el caso de los países más avanzados. No hay valores, ni modelo de servicio civil, ni resistencias de los empleados públicos que puedan impedir los cambios. En este sentido las estrategias de innovación administrativa en América Latina se pueden implementar con una gran profundidad y rapidez.

\section{Definición del problema: el entorno y el intorno del consultor internacional en América Latina}

\subsection{El problema teórico: el isomorfismo institucional}

Desde el neoinstitucionalismo se define el concepto de institución asociándolo genéricamente a la idea de reglas del juego que conforman la interacción entre los distintos agentes implicados en un determinado entorno sociopolítico. Una institución está conformada por normas, procesos y valores que configuran una determinada manera de hacer y genera una suerte de lógica de lo apropiado (MARCH, OLSEN, 1997), que establece los parámetros para el desarrollo de la actividad de los distintos actores implicados. El conjunto de elementos que componen la institución ayuda a los actores a interpretar las situaciones a las que se enfrentan, incidiendo en la definición que éstos hacen de sus propios intereses y expectativas, a partir de sus responsabilidades institucionales y relacionales con el resto de actores, es decir, aquello que se espera, como apropiado, de su papel.

Las organizaciones manifiestan la tendencia a adoptar fórmulas institucionales aceptadas y consolidadas en su entorno de referencia. Las administraciones públicas o determinados sistemas administrativos (como por ejemplo un sistema de servicio civil) son instituciones que también manifiestan la tendencia al mimetismo institucional voluntario o impuesto de modelos de otros contextos que se consideran exitosos. Ésta es una situación bastante común de las administraciones públicas de América Latina que tienden a copiar modelos administrativos anglosajones (por tradición histórica y ahora muy reforzada de la mano de la Nueva Gestión Pública) o de la Europa Continental e incluso de países de su propio contexto (Chile, Costa Rica, etc.). Esta reproducción más o menos mimética de las instituciones puede darse a través de tres tipos de isomorfismo institucional (DiMaggio, Powell, 1991):

- Isomorfismo coercitivo: como resultado de presiones formales e informales ejercidas por otras organizaciones para que se reproduzcan las estructuras y las pautas de funcionamiento. Éste sería el caso, por ejemplo, de las actividades realizadas desde diversos organismos internacionales (y en ocasiones desde determinados Estados avanzados) para el desarrollo de determinadas soluciones institucionales para mejorar la eficacia y la eficiencia de las administraciones públicas de buena parte de los países de América Latina. Aquí el papel del consultor internacional es el de ser un simple instrumento y transmisor de las directrices de estas instituciones internacionales hacia la administración pública objeto de estudio. Esta Administración difícilmente va a poder evitar estos planteamientos normativos ya que de su acatamiento dependerá la financiación de proyectos en el futuro.

- Isomorfismo mimético: como resultado de procesos de imitación de referentes que se consideran líderes o ejemplos a seguir. Así, en entornos caracterizados por cierta ambigüedad en los objetivos, sin un claro criterio para evaluar los resultados, con una importante presencia de elementos simbólicos, las organizaciones tienden a configurarse a partir de un modelo que sirve como referente que se 
considera más legitimado o exitoso. Una parte importante de las administraciones públicas de América Latina cuando no aparece el isomorfismo coercitivo suelen caer en el isomorfismo mimético. Pero muchas veces son los consultores internacionales los que sugieren la implantación sin matices de modelos foráneos lo que los hace como los portadores del isomorfismo mimético.

- Presión normativa: en referencia al impacto de los colectivos profesionales que definen aquello que se considera buenas prácticas a reproducir. El efecto de este isomorfismo se produce mediante dos canales: a) la formación y legitimación basada en los conocimientos especializados vinculados a un determinado ámbito de gestión; b) las redes de profesionales que intercambian conocimientos y favorecen la rápida extensión de las prácticas que se consideran más adecuadas. En este tipo de isomorfismo juega un papel muy importante el proceso de selección de personal que se incorpora en la organización ya que se produce la tendencia a que los diferentes colectivos de profesionales su autoreproduzcan a través del reclutamiento de efectivos con una parecida formación. En América Latina es bastante frecuente que las elites políticas y administrativas se hayan formado en Estados Unidos o en diferentes países europeos. Estas elites tienden a reproducir los modelos de los países en los que han recibido la formación técnica. Los consultores que desean sugerir modelos externos suelen encontrar en estas elites unos poderosos aliados.

En definitiva, las presiones hacia los consultores internacionales y de una parte de éstos hacia las administraciones públicas objeto de estudio multiplican el error de mimetizar modelos administrativos de países avanzados que responden a un contexto y a unos problemas que no tiene ninguna relación con el contexto y con los problemas autóctonos. Por una motivación o por varias se pierde la oportunidad de establecer espacios de cooperación técnica entre los consultores y los agentes internos de la administración pública objeto de análisis para identificar los problemas autóctonos y construir modelos de gestión alternativos en función de los mismos y del contexto y las limitaciones de su entorno nacional.

\subsection{La complejidad real y añadida de la consultoría en el sector público de carácter internacional}

La consultoría institucional (organizativa, de procesos, de recursos humanos, etc.) para organismos públicos de carácter internacional es una actividad mucho más compleja que la consultoría institucional donde el consultor y la institución pública objeto de consultoría pertenecen al mismo contexto nacional. En este sentido, las características diferenciales de la consultoría internacional con relación a la consultoría doméstica son:
1. El consultor suele provenir de un país distinto al que pertenece la Administración pública objeto de estudio.

2. En la mayoría de las ocasiones el consultor pertenece a un país desarrollado y la Administración objeto de estudio a un país en vías de desarrollo.

3. En muchas ocasiones el ente que financia (o cofinancia) la actividad de consultoría es un organismo internacional o un tercer Estado (un país desarrollado que posee planes de cooperación internacional). La Administración pública objeto de la actividad de consultoría no invierte, normalmente, recursos propios en la misma o invierte sólo un pequeño porcentaje del coste total de la actividad de consultoría.

Por otra parte, hay dos grupos de variables que generan interferencias en las actividades de consultoría internacional de carácter institucional: a) variables vinculadas al entorno internacional en el que opera el consultor internacional y b) variables vinculadas al entorno y al intorno de la administración pública objeto de análisis. En concreto, estas variables son:

\section{a) Variables vinculadas al entorno internacional:}

1. Las instituciones internacionales o los Estados desarrollados, que en programas de ayuda al desarrollo, son las que encargan y financian la actividad de consultoría. Estas instituciones pueden tener modelos conceptuales de referencia que imponen o aconsejan a las consultoras que contratan para que desarrollen sus aportaciones en el marco de estos modelos.

2. Los modelos o referentes de Administración pública, de modernización o reforma: las consultoras pertenecen a un país con un modelo administrativo determinado y/o poseen una formación y unas experiencias vinculadas a determinados modelos administrativos que por mecanismos de path dependence suelen proponer directamente la implementación de los mismos sin hacer todos los esfuerzos necesarios de detección de problemas autóctonos, de contextualización de sus modelos de referencia y generándose de forma natural una autolimitación de las potencialidades de creatividad del consultor.

3. Los intereses de empresas multinacionales: las corporaciones empresariales multinacionales tienen muchos intereses sobre los contenidos de la actividad de consultoría. Unas propuestas de mejora institucional en una administración pública de un determinado país pueden plantear muchas diferentes oportunidades de negocio económico: venta de equipos tecnológicos vinculados a la gestión pública directa, conseguir un protagonismo en las estrategias de externalización de los servicios públicos, conseguir una ubicación preeminente en determinados contextos de regulación o de desregula- 
ción, etc. En algunas ocasiones las consultoras forman parte de un complejo holding empresarial con intereses que interfieren directamente en el trabajo de análisis y elaboración de propuestas por la consultora.

\section{b) Variables vinculadas al entorno e intorno de la administra- ción pública objeto de análisis:}

1. Los intereses particulares de las elites políticas y administrativas locales: las elites políticas y administrativas de la Administración pública objeto de mejora tienen sus propios intereses de carácter corporativo-profesional, particular o clientelar que desean priorizar por encima del interés global institucional vinculado al interés general.

2. Los intereses particulares de las elites económicas locales: estas elites, usualmente con vínculos informales con una parte de las elites políticas y administrativas, intentan influir de forma legítima e ilegítima en la actividad de consultoría para maximizar sus potencialidades de negocio.

Finalmente, comentar que los objetivos y tensiones de los actores que operan en el entorno internacional pueden interrelacionarse con los objetivos y actores que operan en el entorno e intorno de la Administración pública objeto de consultoría y que pueden establecer complejas coaliciones transversales de intereses y presiones que incidan sobre el consultor en las dos dimensiones: la internacional y la nacional.

Atendiendo todas estas variables y sus potenciales vinculaciones e interferencias se puede argumentar que la actividad principal y más compleja de un consultor internacional reside en escapar de las distintas tensiones internacionales y domésticas que pretenden capturar a favor de determinados intereses particulares al consultor y a su actividad de consultoría.

En teoría, el consultor cuando recibe una propuesta de trabajo para hacer un diagnóstico y unas propuestas sobre la situación institucional de una administración pública de un país determinado debe tener como objetivo la mejora objetiva de esta administración pública y que, mediante este cambio positivo, atienda con mayor eficacia y eficiencia los intereses generales de los ciudadanos del país de la administración pública objeto de estudio. Pero la actividad de un consultor internacional implica un trabajo intelectual muy complejo que reside en investigar una realidad institucional y de entorno cultural y social compleja y muy distinta a la que conoce y domina de su país de origen. Es decir, la actividad de consultoría siempre implica trabajar con incertidumbre pero en la consultoría internacional se suele trabajar con unas dosis todavía más elevadas de incertidumbre. ¿Cómo se puede reducir la incertidumbre vinculada a la actividad de consultoría internacional? Fundamentalmente hay dos caminos: el empírico y el teórico.
El itinerario empírico implica un profundo trabajo de campo en la realidad y en el contexto cultural y social de la administración pública objeto de estudio que paulatinamente permite articular un diagnóstico y unas propuestas apegadas a la realidad. Pero el itinerario empírico es costoso en tiempo y en esfuerzo intelectual y en ningún momento asegura el éxito de la actividad de consultoría (en ocasiones no se logra elaborar un buen diagnóstico ni unas propuestas útiles con valor añadido). En el caso que se alcance el éxito la actividad de consultoría aportará valor añadido, calidad e innovación. El itinerario empírico asegura que el consultor no esté capturado por intereses en la dimensión internacional pero corre el peligro de estar capturado por intereses particulares de carácter local. La única forma de conseguir superar estas capturas locales es plantear un itinerario empírico lento (si el trabajo de campo se hace muy rápido facilita que existan capturas) que contraste situaciones y opiniones y que también demore un tiempo en negociar con los distintos actores las propuestas de mejora.

El itinerario teórico, en cambio, implica un atajo que facilita reducir rápidamente la incertidumbre intelectual inherente en la actividad de consultoría llegando a extremos en que diagnósticos y propuestas ya están elaborados incluso antes de poseer evidencias empíricas sobre la realidad y los problemas autóctonos de la administración pública objeto de consultoría. ¿¿No es cierto que en muchas ocasiones tenemos la impresión de que algunos consultores internacionales ya poseen un diagnóstico y unas propuestas al bajar del avión que los acerca a la administración pública objeto de estudio?

El itinerario teórico consiste en que los consultores internacionales se dejan capturar de forma deliberada o no deliberada por determinados intereses que definen y defienden modelos y recetarios. En este sentido habría que distinguir dos posibles itinerarios teóricos: a) itinerario teórico no deliberado y b) itinerario teórico deliberado.

El itinerario teórico no deliberado acontece en las situaciones en que el consultor internacional ignora por completo los problemas y la realidad administrativa y de contexto de la administración pública objeto de estudio. Estamos ante aquellas situaciones en que el consultor lo primero que hace es consultar un mapa mundi para ubicar la ciudad y el país donde esta ubicada físicamente la administración que debe analizar. La incertidumbre en estas situaciones es inmensa y las fuentes de información vía internet o vía otros consultores que conocen la zona suelen ampliar la incertidumbre más que reducirla. Los consultores internacionales que se encuentran en esta situación son muy vulnerables y permeables a posibles interferencias y capturas que facilitan allanar su camino y reducir sus incertidumbres. Los consultores multiplican sus contactos con la institución internacional o el aparato de la administración pública del país desarrollado que los ha contratado, instancias en las que siempre hay políticos y altos funcionarios que tienen un discurso oficial o paraoficial en el que son muy evidentes 
los problemas y las potenciales vías de solución de la lejana administración pública objeto de estudio. En este sentido, los consultores reciben el impacto de todo un discurso más o menos estructurado que les permite reducir sus primeros temores e incertidumbres. En este punto, inducidos por terceros o autoinducidos, se van tomando en cuenta modelos administrativos de vanguardia de los países más desarrollados o experiencias exitosas de países en vía de desarrollo. Por ejemplo, hay que aprender del modelo de desregulación de un Estado de EE.UU., del modelo de provisión de servicios de los Länder alemanes todo ello convenientemente contextualizado en un modelo institucional de un lejano país asiático que demuestra, malinterprentando a STIGLITZ (2002), como una institución pública puede tener éxito en un contexto de dificultades económicas y sociales... Además, puede aparecer un portavoz de una corporación internacional que aconseja que el nuevo modelo de gestión debería externalizar algunas de sus actividades o bien debería dotarse de una determinada tecnología informática...

El consultor va encajando piezas hasta que logra articular un diseño más o menos impactante y novedoso pero conceptualmente horroroso y, lo más importante y grave: totalmente desvinculado de los problemas reales de la administración objeto de análisis. El consultor que ha optado por el itinerario teórico no deliberado cuando contacta directamente con la administración objeto de estudio (cuando inicia el trabajo de campo) lo hace con unas lentes conceptuales, con unos prejuicios teóricos, que no le permiten percibir las especificidades, los problemas autóctonos de la realidad objeto de análisis. Su mayor preocupación consiste en encajar una realidad extraña e incómoda al modelo conceptual y a los referentes que lleva en el maletín. El resultado de su actividad no será un conjunto de propuestas que solucionen los problemas reales de la institución pública, sino unas propuestas que coexistan y logren convivir con los problemas de la institución que en el futuro van a persistir o a multiplicarse

Por otra parte, el itinerario teórico deliberado es muy parecido al anterior pero con la diferencia de que el consultor es plenamente consciente en la artifiosidad de toda su metodología y bases teóricas y tiene muy claro que su papel consiste en defender intereses públicos o privados de organizaciones ajenas a la institución objeto de consultoría. Más que un consultor es un vendedor indiferente a que los artículos que oferta sirvan o no sirvan o incluso empeoren la situación de la administración pública objeto de intervención. El itinerario teórico deliberado implica unos valores de fondo y una metodología que la mayoría de códigos deontológicos lo definen como escasamente ético y profesional.

Otra forma de categorizar los distintos modelos de consultoría internacional sería mediante su agrupación en consultoría fordista frente a consultoría artesanal (ver tabla 1).

\begin{tabular}{|c|c|c|c|c|}
\hline \multicolumn{3}{|c|}{ Consultoría fondista } & Consultoría artesanal & \\
\hline No deliberada & Deliberada & Rápida & Lenta & \\
\hline $\begin{array}{l}\text { Permeable a los grandes } \\
\text { referentes internacionales y } \\
\text { a todo tipo de presiones } \\
\text { internacionales } \\
\text { institucionales y particulares. }\end{array}$ & $\begin{array}{l}\text { Domina una agenda oculta } \\
\text { con base a intereses ajenos a } \\
\text { la organización y del país } \\
\text { objeto de estudio. }\end{array}$ & $\begin{array}{l}\text { No permeable a referentes e } \\
\text { intereses internacionales pero } \\
\text { muy permeable a intereses } \\
\text { locales particulares. }\end{array}$ & $\begin{array}{l}\text { Totalmente focalizada en la } \\
\text { organización objeto de } \\
\text { análisis atendiendo su } \\
\text { contexto y limitaciones. }\end{array}$ & Características \\
\hline $\begin{array}{l}\text { Se transfieren problemas y } \\
\text { soluciones } \\
\text { descontextualizadas de la } \\
\text { realidad objeto de estudio. } \\
\text { Se convive con los problemas } \\
\text { reales. }\end{array}$ & $\begin{array}{l}\text { Se inventan las disfunciones } \\
\text { para imponer determinadas } \\
\text { soluciones. Persisten los } \\
\text { problemas reales y se generan } \\
\text { nuevos problemas. }\end{array}$ & $\begin{array}{l}\text { Se legitiman los problemas } \\
\text { manifestados por } \\
\text { determinadas elites que } \\
\text { prescriben soluciones } \\
\text { satisfactorias para estas elites. }\end{array}$ & $\begin{array}{l}\text { Se detectan los problemas } \\
\text { reales y se proponen } \\
\text { soluciones que permiten } \\
\text { solventar una parte } \\
\text { significativa de los } \\
\text { problemas. }\end{array}$ & Resultados \\
\hline
\end{tabular}

Fuente: Elaboración propia. 
La consultoría fordista implica una actividad rápida, estandarizada y que persigue fundamentalmente el máximo beneficio económico para la consultora y/o el consultor. A la consultoría fordista no le preocupan los problemas autóctonos (incluso los niega: "todas las organizaciones tienen idénticos problemas con independencia que sean privadas o públicas y con independencia de su contexto económico y social" es su base argumental) y aporta unas soluciones universales válidas tanto para Colombia como para Chile, Nueva Zelanda o Tailandia. Funciona con referentes teóricos predefinidos y con un trabajo de campo rápido y formal. El resultado de esta actividad suele ser que no resuelve en absoluto los problemas y se limita a coexistir con los mismos. El modelo fordista de consultoría también se utiliza cuando el consultor tiene intereses ocultos (agenda oculta) en la actividad de consultoría que desarrolla ya que su objetivo es defender determinados intereses particulares de Estados, Instituciones internacionales $y$, fundamentalmente, empresas multinacionales. Se trata de una actividad corrupta que utiliza el modelo fordista ya que es el que mejor se adapta a sus intereses. Es obvio que el resultado de esta consultoría no permite solucionar los problemas reales de la administración objeto de estudio y que suele empeorar su situación, ya que de lo que se trata es de inventarse los problemas para facilitar que se implementen las estrategias del recetario que beneficia a los intereses institucionales o internacionales ocultos.

Pero el modelo fordista no se limita a una metodología teórica sino también agrupa una parte de la metodología empírica cuando ésta está vinculada a un trabajo de campo excesivamente rápido y formal. El resultado de esta metodología es un informe que no aporta valor añadido ya que no detecta los problemas reales de la organización objeto de estudio y suele detectar los problemas que más interesan a las elites políticas, administrativas y económicas con más recursos para capturar y manipular la agenda profesional del consultor.

Un modelo alternativo a la consultoría fordista es la consultoría artesanal que se caracteriza por no tener apriorismos conceptuales y por realizar un trabajo de campo lento y seguro orientado a detectar los problemas reales de la administración pública analizada y a contextualizarlos en las dimensiones culturales, sociales y económicas. Este modelo construye propuestas fundadas en los problemas reales con la colaboración de las elites políticas y administrativas preocupadas por la eficacia y la eficiencia y que defienden el interés general.

\section{Propuestas tentativas: esbozo de la consultoría institucional para América Latina como una actividad útil}

Es obvio que una correcta consultoría institucional de carácter internacional que sea útil para las administraciones públicas de los países de América Latina debería ser una consultoría de carácter artesanal fundada en un itinerario empírico lento que permita detectar los problemas autóctonos y plantear unas propuestas de mejora y cambio contextualizadas en los fundamentos institucionales de la organización o de la política analizada analizada y en el contexto de su entorno económico y social. Las propuestas deben ser no sólo realistas sino también evitar al máximo rupturas con la tradición institucional de la organización objeto de estudio (JoRDAna, Ramió, 2002). El diagnóstico y las propuestas deben hacerse con la colaboración de las elites políticas y profesionales más comprometidas en la defensa de los bienes públicos y del interés general sorteando los intentos de captura de las elites políticas y profesionales vinculadas a intereses corporativos y privados. La aportación del consultor debe ser un dictamen y no un dictado impuesto por intereses específicos de carácter internacional o nacional. Finalmente, las propuestas deben aportar valor añadido, innovar para incrementar la calidad pero también que sea sostenible en el futuro atendiendo las bases institucionales de la organización analizada y de su contexto político, económico y social. En concreto los elementos a tener en cuenta para conseguir una positiva actividad de consultoría internacional serían:

1) Actitudes y actividades a desarrollar antes de abordar el trabajo de campo in situ:

- Informarse sobre la realidad política, institucional, económica y social del país en el que está ubicada la administración pública objeto de estudio.

- Estar al día sobre modelos administrativos comparados, sobre las distintas experiencias de reforma y modernización de los países más avanzados y de los países en vías de desarrollo pero sin socializarse en exceso con ninguno de ellos. Hay que ser consciente de que la mayoría de las experiencias de innovación son el producto de un contexto específico.

- No dejarse influir por opiniones oficiales y extraoficiales de la institución que encarga y financia la acti- 
vidad de consultoría. Tampoco hay que dejarse influir por otros actores: instituciones públicas del país de origen del consultor, opiniones de otros consultores, etc.

\section{2) Actitudes y actividades vinculadas al trabajo de campo para} elaborar el diagnóstico:

- Detectar las elites políticas y locales más comprometidas con la institución y con la defensa de los intereses generales.

- Detectar las elites políticas y locales que defienden intereses corporativos o particulares.

- Hacer un trabajo de campo intenso y extenso orientado a detectar los problemas reales. Ser muy plural en la recogida de información: contactar no sólo con altos cargos sino también con efectivos ubicados en un nivel intermedio y operativo, con actores del entorno de la organización (colectivos de ciudadanos, Stakeholders), etc.

- Ser muy transparente en el trabajo: presentarse profesionalmente (curriculum personal, etc.), identificar claramente la instancia que estimula y financia el estudio, la metodología empleada y los potenciales impactos del estudio. Hay que ser transparente y proporcionar la máxima información sobre el estudio para evitar informaciones informales alternativas y para intentar evitar desde el principio la resistencia al cambio.

- Elaborar el diagnóstico con la colaboración de los agentes internos de la institución analizada. En especial elaborar el diagnóstico con la colaboración de las elites políticas y profesionales, previamente detectadas, que se preocupan por la eficacia y eficiencia de la institución en la defensa de valor público y del interés general.

\section{3) Actitudes y actividades vinculadas al proceso de elaboración} de las propuestas de cambio:

- Diseñar unas propuestas realistas que tengan la posibilidad de ser puestas en práctica por la institución objeto de estudio.

- Diseñar unas propuestas que tengan en cuenta el contexto institucional, político, económico y social de la institución analizada.
- Derivado de los puntos anteriores, intentar evitar proponer modelos institucionales que sean radicalmente diferentes a la situación anterior y que respondan a modelos ajenos al sistema político y administrativo del país donde está ubicada la institución objeto de estudio (JoRDANA, RAMió, 2002).

- Negociar las propuestas de mejora e innovación con la mayoría de los actores internos, tanto los que defienden el interés general como los que defienden determinados intereses particulares. Sólo mediante un proceso abierto de negociación que permita estrategias de mejora pactados es posible la implementación futura de las propuestas.

\section{4) Los valores de un consultor internacional:}

- Un consultor debe trabajar con un marco conceptual de valores propios de ética profesional y personal que permitan canalizar su actividad de consultoría. Para cualquier actividad profesional es muy importante poseer su propio código deontológico pero esta necesidad es absolutamente imprescindible para un consultor que trabaja en el ámbito público y que, por tanto, debe defender los valores públicos y el interés general como si de un empleado público se tratara. Y todo ello es todavía más imprescindible cuando la actividad de consultoría tiene una proyección internacional, ya que esta actividad tiende a generar confusión en términos de valores públicos por la mezcla entre los valores del país donde se realiza la actividad de consultoría, los valores de las instituciones que financian el proyecto técnico y los valores del entorno del país de origen de la consultora y de los consultores. Esta confusión de valores puede generar importantes incertidumbres en los consultores y éstos corren el peligro de adoptar valores inadecuados o de realizar su práctica profesional en un vacio deontológico. Por esta razón es muy importante que el consultor tenga sus propios valores públicos, su propio código deontológico y responda con esta base ética-conceptual a estas incertidumbres. La tabla 2 ofrece un ejemplo de esquema conceptual de carácter deontológico para un consultor internacional que debería siempre tener presente durante todas las fases de su práctica profesional. 
Tabla 2

Valores profesionales y corporativos de un consultor internacional

\begin{tabular}{|c|c|}
\hline Misión & $\begin{array}{l}\text { Dar apoyo a las instituciones públicas y a sus equipos de gobierno, para satisfacer las necesidades colectivas de los } \\
\text { ciudadanos mediante servicios y/o actuaciones públicas. }\end{array}$ \\
\hline Visión & $\begin{array}{l}\text { Impulsar el Estado del Bienestar (o una aproximación realista en función de la riqueza del país) mediante actuaciones } \\
\text { públicas dirigidas a los ciudadanos. }\end{array}$ \\
\hline Entorno: Amenazas & $\begin{array}{l}\text { - Presiones de organizaciones internacionales públicas. } \\
\text { - Presiones de corporaciones privadas intenacionales. } \\
\text { - Presiones partidistas no institucionales. } \\
\text { - Presiones de corporaciones privadas locales. }\end{array}$ \\
\hline $\begin{array}{l}\text { Entorno: } \\
\text { Oportunidades }\end{array}$ & $\begin{array}{l}\text { - Necesidades colectivas emergentes. } \\
\text { - Problemas colectivos no resueltos. } \\
\text { - Actuaciones o servicios públicos mejorables. }\end{array}$ \\
\hline Objetivos & $\begin{array}{l}\text { - Diagnosticar correctamente. } \\
\text { - Proponer nuevas actuaciones. } \\
\text { - Mejorar prestaciones de los servicios públicos. } \\
\text { - Proponer actuaciones adecuadas y viables. }\end{array}$ \\
\hline Parámetros de trabajo & $\begin{array}{l}\text { - Coherencia: actuar con un solo objetivo y no en direcciones y sentidos contrarios de forma simultánea. } \\
\text { - Honradez. } \\
\text { - Valor añadido: aportar capacidades de innovación. } \\
\text { - Pragmatismo y viabilidad: las propuestas formuladas deben ser realistas y asumibles. } \\
\text { - Respeto: respeto a los valores institucionales propios y positivos de cada país. } \\
\text { - Formación continua: adquisición permanente de conocimientos y herramientas de trabajo. }\end{array}$ \\
\hline
\end{tabular}

Fuente: Adaptación de J. SANTOLARIA.

* Un borrador de este artículo se presentó como ponencia en el panel "La capacidad institucional de los organismos públicos" del VII Congreso Internacional del CLAD celebrado en Lisboa el octubre de 2002. El autor agradece los comentarios de
Jordi Santolaria, Jorge Hintze, Oscar Oslack, Sonia Ospina y Alain Tobelem.

** Profesor titular de Ciencia Política y de la Administración en la Universitat Pompeu Fabra.

\section{Bibliografia}

Dimaggio, P., Powell, W. (1991): The New Institutionalism in Organizational Analysis, Chicago, Chicago University Press.

Hood, C. (1998): The Art of the State. Culture, Rhetoric, and Public Management, Oxford, Oxford University Press.

Jordana, J., Ramió, C. (2002): Diseños Institucionales y Gestión de la Politica Comercial Exterior en América Latina, Buenos Aires, Banco Interamericano de Desarrollo.

MarCH, J.G., OlsEN, J.P. (1997): Redescubrimiento de las Instituciones, México, Fondo de Cultura Económica.

Mas, J., Ramió, C. (1998): La Auditoría Operativa en la Práctica. Técnicas de Mejora Organizativa, México, Alfaomega.
MickletheWAit, J., WoOldRiege (1998): La Hora de los Gurus. Visionarios y Nuevos Profetas de la Gestión Empresarial, Madrid, Alianza Editorial.

Ramió, C. (2001): "Los Problemas de la Implantación de la Nueva Gestión Pública en las Administraciones Públicas Latinas: Modelo de Estado y Cultura Institucional", Reforma y Democracia, núm. 21.

Ramió, C. (2002): "Las Auditorías de Gestión: La Evaluación de las Dimensiones Organizativas en la Administración Pública”, en Bañón, R. (Comp.), La Evaluación de la Acción y de las Políticas Públicas, Madrid, Díaz de Santos.

Santolaria, J. (2002): Criterios de Trabajo de los Consultores de Administraciones Públicas, mimeo.

STIGLITZ, J.E. (2002): El Malestar en la Globalización, Madrid, Taurus. 